\title{
Common Breeding Techniques in Rice (Orzya sativa L.): Review
}

\author{
Mohammed Aman* and Hayat Worku \\ Ethiopian Institute of Agricultural Research, Jimma Agricultural Research Centre, Jimma, Ethiopia \\ *Corresponding Authors: Mohammed Aman, Ethiopian Institute of Agricultural Research, Jimma \\ Agricultural Research Centre, Jimma, Ethiopia
}

\begin{abstract}
Rice (Orzya sativa L.) is a staple and most important security food crop consumed by almost half of the world's population. More rice production is needed due to the rapid population growth in the world. Therefore, in order to increase the productivity and improve it is resistance for biotic and a biotic stress, different breeding techniques has been applied in rice. And this paper was objected to review and summarize the commonly used breeding methods in rice. One of the oldest and widely used breeding techniques is selection. In India variety like IR8 was improved through this method and mostly used for traits that have low inheritance. Hybridization is the other methods which have yield advantage of about 10\% - $15 \%$ over best inbred varieties were introduced in China. Pedigree method has by far been the most popular method in rice breeding and variety IR64 which is wide adaptation, early maturity and improved quality was developed through this technique. One of the most recent and efficient method in rice breeding is molecular marker assisted. It used DNA markers located near the gene or allele co-segregate with the trait of interest across generations makes it easy to identify the presence or absence of particular genel allele in the laboratory itself without growing the crop. Overall, in order to secure the need of the growing population, having different breeding techniques which improve and increase the resistance of rice varieties for variable climate is highly relevant.
\end{abstract}

Keywords: Hybridization, molecular marker assisted Pedigree, Rice, and Selection.

\section{INTRODUCTION}

Rice (Oryza sativa L.) is the second dominantly grown cereal crop and the staple food for more than half of world's population, providing calorie intake of nearly 1.5 billion people in Africa and Latin America (FAO,2017). In Ethiopia rice was introduced in the early 1970. Like other major commodities, rice is cultivated as one of the strategic crop for food security in Ethiopia (Abebaw, 2020). The average growth rate of rice yield was $3.68 \%$ per year in the early 1980 's but has decreased to $0.74 \%$ per year in the late 1990 's. This is due to biotic and a biotic factors, which results for increasing the cost of production and low yielding varieties. In Ethiopia the national mean grain yield productivity of rice showed a constant increase from $2001\left(1.6\right.$ tones ha $\left.{ }^{-1}\right)$ till $2008\left(2.9\right.$ tonesha $\left.^{-1}\right)$ and followed by a sharp drop in 2009 (Figure 1).

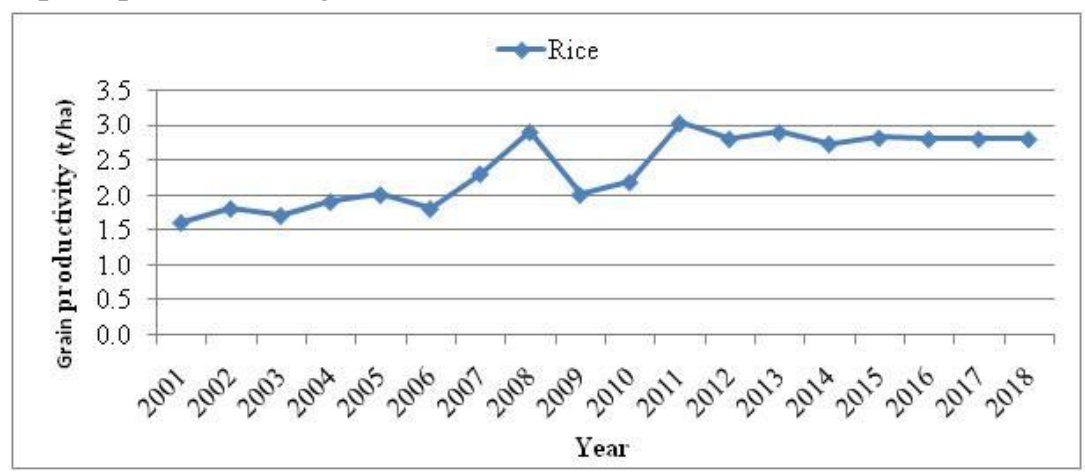

Source: $C S A(2001-2018)$

\section{Figure1. Mean Grain Yield Productivity of Rice in Ethiopia.}

However, the dramatically increasing of human population at worldwide has increased the demand for rice production, requiring an improvement of 50\% by the year 2025 (Li et al., 2010). This showed that the population increments and productivity of rice are not well correlated and needs different breeding 
techniques for rice varieties that produce higher yields under available land for cultivation. The decisive goal of crop breeding is to develop varieties with high yield potential, resistance to a biotic and biotic stress with desirable agronomic characteristics. In rice breeding, the most important qualities sought by breeders have been high yield potential; resistance to major diseases and insects; and improved grain and eating quality (Khan et al., 2015).

Globally the genus Oryza has 25 species, of which Orzya sativa and Orzya g. are the only dominant cultivated. In Ethiopia Orzya sativa is the widely grown and found under cultivated. Rice is not indigenous crop to Ethiopia, the source of germ plasm until now is through introduction. Overall, to meet the above breeding goals, the commonly used breeding strategies and methods in rice breeding are: Selection, hybridization, pedigree methods and Molecular marker assisted. Therefore, the objective this paper was to review and summarize the commonly used breeding technique in rice.

\section{DESCRIPTION OF RICE (ORZYA SATIVA L.)}

The Genus Orzya belongs to the tribe Orzyeae of the family poaceae. The primary centre of origin of the cultivated rice according to archeological and historical evidence is South-east Asia for $O$. sativa and Africa for $O$. glaberrima. The genus Oryza is distributed throughout the tropics and subtropics of the world. It has 25 species of which 23 species are wild and only two species viz. Oryza sativa and Oryza glaberrima are cultivated species. Oryza sativa is mainly cultivated in the Asiatic region while O. glaberrima in Africa. The genus contains both diploid $(2 n=24)$ in addition to tetraploid $(2 n=48)$ species. Rice is an autogamous plant propagating mainly through seeds produced by self pollination (Roy and Vijay., 2013). Even though rice is a self-pollinated crop, natural out crossing can occur up to 0.5 to $4 \%$ (Oka, 1988). Most of the wild species have longer stigma, which protrudes well outside the spikelet facilitating increased percentage of out crossing however, their percentage in terms of out crossing are various within the ecotypes of $O$. sativa. Oka (1988) reported that indica have higher percentage of out crossing than japonica.

Introductions from IRRI during 1960s have led to green revolution. Characterization of germplasm based on identifiable stable morpho-physiological traits has enabled their use for economic importance. Characterization of wild rice species has revealed their importance as potential donors for various biotic and abiotic stresses. A number of elite lines and cultivars characterized with resistance to biotic and abiotic stesses and quality characters were developed through conventional breeding using the available genetic variability in the germplasm of $\mathrm{O}$. sativa to the maximum extent (Roy and Vijay, 2013). Currently various breeding technique has been used beyond convectional breeding like molecular assisted marker. Depend on the objectives of breeding and crops, the technique that has been used are different. However, the commonly used breeding techniques which improve and increase the productivity of rice are discussed below.

\subsection{Commonly Used Breeding Techniques in Rice}

\subsubsection{Selection Methods}

Mass selection is the oldest selection method of plant breeding and probably the most used in plant breeding over time. It is the widely used in rice breeding. Especially it is highly used for traits with lower heritability (h2), such as grain production (Abreu et al., 2010). The progenies of the best population are expected to be superior to the progeny of a random sample of the population in this method. However, there is difficulty in evaluating the efficiency of mass selection methods is that there is no information about the genotype of the individual selected. In rice verity like IR8 was developed and improved through this method (Peng et al., 2008). IR8 is the first high-yielding modern rice cultivar, was released by IRRI in 1966. It was the start of the "green revolution" in Asia. IR8 is a semi dwarf with profuse tillering, stiff culms, erect leaves, photo period insensitivity, high N responsiveness, and high harvest index compared with traditional cultivars.

\subsubsection{Hybridization}

Heterosis is the superiority of hybrid individuals compared to inbred individuals. Hybrid can be developed through crossing of two different species which have different traits in several generations. Hybrid vigor reduced rapidly through generations of selfing, indicating that, whatever is the mechanism underlying heterosis, it is due to the presence of heterozygous loci. The two problems in hybrid breeding methods are: (i) the need to improve at least two populations toward agronomic 
adaptation, while keeping them genetically distant enough to express strong heterosis, and (ii) developing efficient seed production of selected hybrids, such that the cost of seed production does not offset the value of the additional yield resulting from heterosis (Breseghello and Coelho., 2013). Rice hybrids with a yield advantage of about $10 \%-15 \%$ over best inbred varieties were introduced in China in mid 1970s and are now planted to about $45 \%$ of the rice land in that country. In china to improve the rice yield and resistance to pests, three hybrid varieties such as Hunan, Jiangxi and Sichuan were developed through hybridization methods (Li et al., 2007). Similarly, in India Sudhir" was another variety which has been developed from the "FR13A" × "Biraj" crosses (Khan et al., 2015).

\subsubsection{Pedigree Methods}

The pedigree method has by far been the most popular method used in rice breeding (Peng et al., 2008). In these methods individual plants are selected from segregating F2 generation followed by selfing and selection of required characters up to F6 generation.

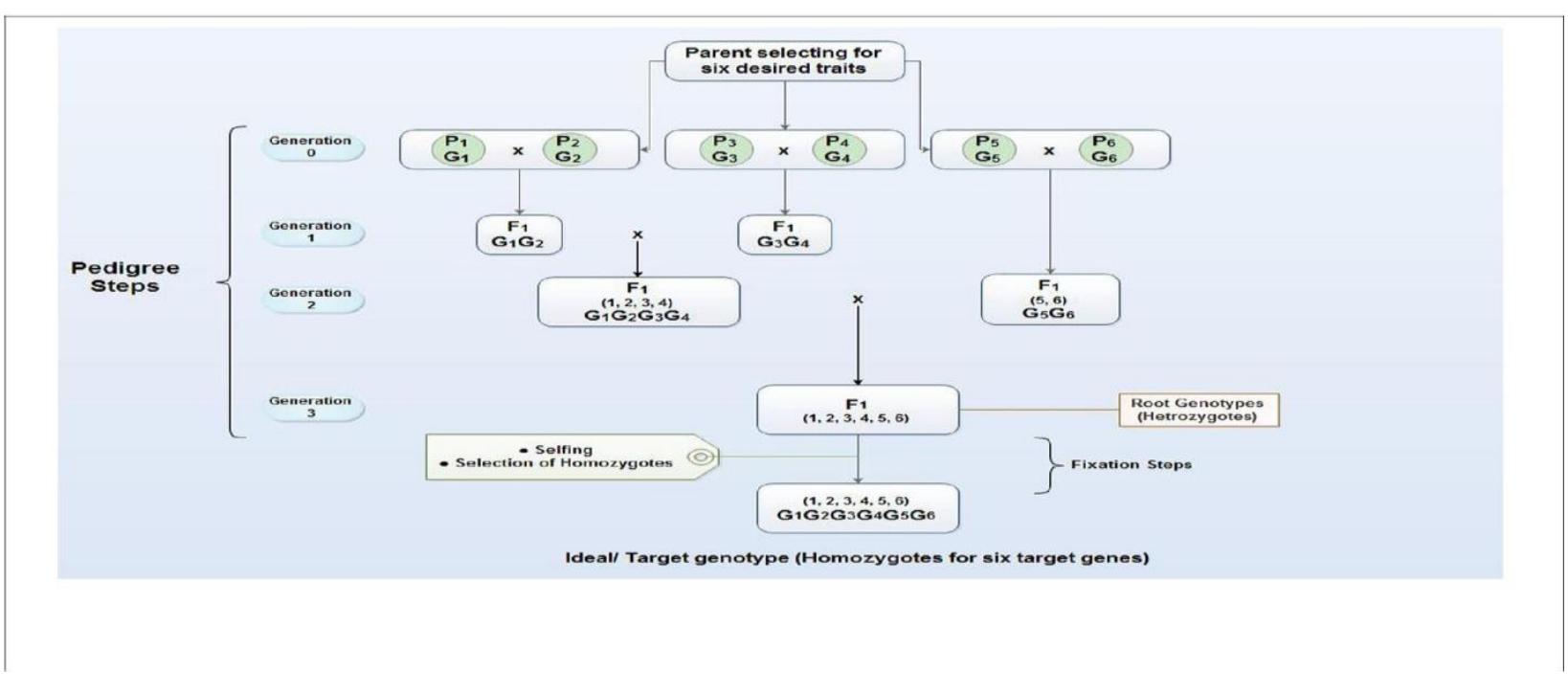

Source: Ashkani et al., 2015

Figure2. Pedigree Method Steps in Plant Breeding.

In rice, different varieties were developed through pedigree methods. For instance, IR64 was released in the Philippines in 1985. It replaced IR36 in most growing areas and spread rapidly in new areas. Because of its wide adaptation, early maturity, and improved quality, it became a standard for highquality rice and was highly desired by the rice industry. Because of its popularity, it has been used widely as a representative indica variety in research studies (Mackill and Khush., 2018).

\subsubsection{Molecular Marker Assisted}

The marker assisted breeding is used to facilitate the selection of trait of interest combinations that occur naturally within a species or via the introduction of alien genes using transgenic. It involves the use of molecular marker which used to identify the presence, or absence, of a desired plant phenotype or phenotypic component based on the sequences of molecular markers located in or near the genes controlling the phenotype. DNA markers located near the gene or allele co-segregate with the trait of interest across generations makes it easy to identify the presence or absence of particular gene/ allele in the lab itself without growing the crop (Coffman, 2004). A lot of rice varieties were developed through this method. For example, Swarna Sub1, IR64 Sub1, Samba Mahsuri Sub1 by introgression of Sub1 locus from FR13A was developed by IRRI for submergence tolerance. Likewise, in India, the bacterial blight resistant varieties were developed by introgression of bacterial blight resistant genes into Pusa Basmati 1 and Samba Mahsuri through marker assisted selection (Roy and Vijay., 2013).

\section{CONCLUSION}

Overall, these paper in touch the most common breeding techniques which improve the productivity, resistance to a biotic and biotic stress and quality of the rice. With the current increments of the population and variable climate, producing a crop like rise which is the stable and half of the world 
population depend on is very important. Thus, different breeding methods have been applied in rice. In India variety like IR8 was improved through selection method, especially traits that have low inheritance. Hybridization is the other methods which have yield advantage of about $10 \%-15 \%$ over best inbred varieties were introduced in China. Pedigree method has by far been the most popular method in rice breeding and variety IR64 which is wide adaptation, early maturity and improved quality was developed through this technique. Molecular marker assisted is the most recent and efficient method. It involves DNA markers makes it easy to identify the presence or absence of particular gene. In India, the bacterial blight resistant varieties were developed by introgression of bacterial blight resistant genes into Pusa Basmati 1 and Samba Mahsuri. Overall, these methods create an opportunity to improve the rice production and make resistance to a biotic and biotic stress.

\section{REFERENCES}

[1] Abebaw Dessie, 2013. Rice Breeding Achievements, Potential and Challenges in Ethiopia. International Journal of Research Studies in Agricultural Sciences, 6:35-42.

[2] Abreu, G.B., Ramalho, M.P., Toledo, F.H.R.B. and Souza, J.C., 2010. Strategies to improve mass selection in maize. Maydica, 55(3/4), 219-225.

[3] Ashkani, S., Rafii, M.Y., Shabanimofrad, M., Miah, G., Sahebi, M., Azizi, P., Tanweer, F.A., Akhtar, M.S. and Nasehi, A., 2015. Molecular breeding strategy and challenges towards improvement of blast disease resistance in rice crop. Frontiers in plant science, $6: 886$.

[4] Breseghello, F. and Coelho, A.S.G., 2013. Traditional and modern plant breeding methods with examples in rice (Oryza sativa L.). Journal of agricultural and food chemistry, 61(35): 8277-8286.

[5] Coffman R, McCouch SR, Herdt RW. 2004. Potentials and limitations of biotechnology in rice. FAO Rice Conference, Rome, Italy, 12-13 Feb., 2004.

[6] Collard, B.C.Y., Septiningsih, E.M., Das, S.R., Carandang, J.J., Sanchez, D.L., Kato, Y., Ye, G., Reddy, J.N., Singh, U.S., Aula, K.M. and Venuprasad, R., 2013. Developing new flood-tolerant varieties at the International Rice Research Institute (IRRI). SABRAO Journal of Breeding \& Genetics, 45(1).

[7] CSA (2001-2018). Central Statistical Agency. The Federal Democratic Republic of Ethiopia, Central Statistical Agency. Report on Area and Production of Major Crops (Private Peasant Holdings, Meher Season), Statistical Bulletin, and Addis Ababa, Ethiopia.

[8] Food and Agricultural Organisation (FAO) (2017). Rice information. Food and Agricultural Organisation of the United Nations, Rome, Italy 19(2):20-27.

[9] Jiming li et al., Yeyun Xin ,Longping Yuan , 2007 Hybrid Rice Technology Development Ensuring China's Food Security. International food policy research institute, 1-40.

[10] Jin, L., Lu, Y., Xiao, P., Sun, M., Corke, H. and Bao, J., 2010. Genetic diversity and population structure of a diverse set of rice germplasm for association mapping. Theoretical and Applied Genetics, 121(3) :475-487.

[11] Khan, M.H., Dar, Z.A. and Dar, S.A., 2015. Breeding strategies for improving rice yield: review. Agricultural Sciences, 6(05), 467.

[12] Khush G. S. (2001). Green revolution: the way forward. Nat. Rev. 2: 815-22.

[13] Mackill, D.J. and Khush, G.S., 2018. IR64: a high-quality and high-yielding mega variety. Rice, 11(1), p.18.

[14] Oka HI. 1988. Origin of cultivated rice. Japan Sci Soc Press, Tokyo. 245.

[15] Peng, S., Khush, G.S., Virk, P., Tang, Q. and Zou, Y., 2008. Progress in ideotype breeding to increase rice yield potential. Field Crops Research, 108(1), 32-38.

[16] Roy, B. and Vijay, D., 2013. Chapter-6 Hybrid Rice in Tropical Countries. Breeding, Biotechnology and Seed Production of Field Crops, 155.

Citation: Mohammed Aman and Hayat Worku, (2021). "Common Breeding Techniques in Rice (Orzya sativa L.): Review", International Journal of Research Studies in Agricultural Sciences (IJRSAS), 7(9), pp. 27-30. DOI: http://dx.doi.org/ 10.20431/2454-6224.0709005

Copyright: () 2021 Authors. This is an open-access article distributed under the terms of the Creative Commons Attribution License, which permits unrestricted use, distribution, and reproduction in any medium, provided the original author and source are credited. 